\title{
Analysis of the fundamental characteristics of diamond-like crystals and low-dimensional structures
}

\author{
V.G.Litovchenko* \\ Institute of Semiconductor Physics, National Academy of Sciences of \\ Ukraine, 45 Nauki avenue, Kiev 03028, Ukraine
}

Received April 8, 2003, in final form February 12, 2004

\begin{abstract}
The principle has been developed for systematizing the diamond-like crystals with tetrahedral structure of the elementary cells and with valence chemical bonds, based on the calculation of the lattice constant. The approach proposed permits to predict basic parameters such as energy gap $E_{\mathrm{g}}$, electron affinity (optical work function) $\mathrm{X}$, mechanical hardness $\mathrm{H}$, melting temperature $T_{\mathrm{m}}$, optical phonon frequency etc. These parameters have been calculated and the table is presented for a number of chemical compositions. For materials with mixed chemical bonds (valence and ionic) the corrections can be calculated using Pouling electronegativity conception. The comparison with experiment demonstrates good agreement between the latter and the proposed procedure.
\end{abstract}

Key words: diamond-like crystal systematization, electron affinity, high melting temperature

PACS: 81.05.Bx, 81.05.Cy, 74.78.-w

\section{Introduction}

The development of high technologies presents new possibilities for the creation of many different classes of materials including semiconductors with unusual and in some cases extreme properties, such as very large bond energy, superhigh mechanical and radiation hardness, high sensitivity to radiation, optical and laser properties etc. This is especially related to the creation of nanocluster materials when size dependent properties open a new type of the solid state - pseudomolecular solid state, semiconductors with coexisting electron state bands and discrete levels, new types of electron and phonon k-dispersion relations etc.

The proposal for systematization of the crystal properties and some general approach for band engineering of the semiconductor materials is rather desirable and

*E-mail: LVG@isp.kiev.ua 
up-to-date. As it is known, concerning chemical elements (Mendeleev table etc.) such a systematization is based on the atomic weight, which actually occurred as dependence on the configuration of the electron shells.

Below we will describe the method for the construction of different dimension dependent tetrahedral (diamond-like) crystals with valence bonds based on the band structure and hence the prediction of semiconductor materials with extreme properties. The analysis is based on the use of the known theoretical dependence of the energy band (conduction and valence) on the lattice constant $L$, i.e. on the distance between the atoms, $r_{A B}=a_{A}+a_{B}$, directly related to $L$ (in particular, for tetrahedral lattice configurations: $L=2 / \sqrt{3} r_{A B}, a$ is the valence radius). Such a dependence was obtained in the series of publications (by Shockley, Slater, Ioannopoulos, Harrison et al., see [1]). An important and unexpected point is that this dependence is nearly the same for all cubic semiconductor crystals of the fourth group in the periodical table of elements, namely for carbon in its diamond modification, silicon, germanium in cubic modification as well as the compounds of these crystals, such as $\mathrm{SiC}, \mathrm{SiGe}$ and others rather rarely used, such as GeC, GeSn, SiSn. It is also possible, using the calculation of the effective tetrahedral length of the cubic complexes $\mathrm{A}_{x} \mathrm{~B}_{1-x} \mathrm{C}$ (e.g., $\mathrm{Si}_{x} \mathrm{C}_{1-x} \mathrm{Ge}, \mathrm{Si}_{x} \mathrm{C}_{1-x} \mathrm{Sn}$ etc.):

$$
L=\frac{2}{\sqrt{3}}\left(x a_{\mathrm{Si}}+(1-x) a_{\mathrm{C}}+a_{\mathrm{Ge}}\right)
$$

to estimate such fundamental characteristics as valence energy gap, optical workfunction (electron affinity) of alloys of the elements III to V groups and II-VI groups as well as more complex combinations of elements of II and III groups with elements of $\mathrm{V}$ and VI groups when the valid valence accordance rules (sum of valence electrons must be equal to number of empty orbitals for every elementary cell) are in agreement with the mentioned dependence $\varepsilon(L)$.

Electronic properties of the FC-cubic crystals with dominating valence bonds were analysed in different approximations (LCAO, tight-binding pseudopotential up to ab-initio in Carparinello approach) and have been considered by many authors (Shockley, Slater, Harrison etc., see [1]). The important general conclusion that is possible to draw is that the first energy bands (conductance band edge $E_{\mathrm{C}}$, valence band energy $E_{\mathrm{V}}$ for $k=0$ ) dependence on the lattice length constant $L$ is common for all crystalline materials of the fourth group of the periodical table of elements $\left(\beta-\mathrm{C}, \mathrm{Si}, \mathrm{Ge}, \mathrm{Sn}, \mathrm{SiC}, \mathrm{SiGe}, \mathrm{IV}_{A}, \mathrm{IV}_{B}\right.$ as well as for many III-V crystals with relatively small part of type of bonds).

It is possible to formulate the physical reason for such a conclusion, namely because the energy of valence (as well as ionic and metal) bonds is determined by the matrix elements of the nearest atomic interaction through $\mathrm{sp}^{3}$ hybrid orbital overlap: $H_{12(21)}$

$$
\begin{gathered}
V_{S}=\left(\Psi_{a, b}^{S}|H| \Psi_{a, b}^{S^{*}}\right), \quad V_{P} \equiv V_{2}=\left(\Psi_{a}^{P}|H| \Psi_{b}^{P}\right), \\
E_{\mathrm{C}}=V_{S}+V_{2}
\end{gathered}
$$


and bonding (valence) bond as

$$
E_{\mathrm{V}}=V_{S}-V_{2}
$$

So, the gap energy (in valent case) is directly determined by the matrix element $V_{2}$ :

$$
E_{\mathrm{CV}}=E_{\mathrm{C}}-E_{\mathrm{V}}=2 V_{2} .
$$

For mixed bonds (valence and ionic) the energy gap $E_{\mathrm{g} \Sigma}$ consists of both valence $E_{\mathrm{gV}}$ and ionic $E_{\mathrm{gi}}$ parts:

$$
E_{\mathrm{g} \Sigma}=E_{\mathrm{gV}}+E_{\mathrm{gi}} .
$$

Using Pauling relation for the degree of ionicity I (which can be easily estimated from electronegativity $\mathrm{X}$ of elements $\mathrm{A}, \mathrm{B}$ ) it is possible to determine the $E_{\mathrm{g} \Sigma}$ value from the known value of $E_{\mathrm{gV}}$ :

$$
\begin{gathered}
I \cong 0.2 \Delta X^{2}=\left(X_{A}-X_{B}\right)^{2} \times 0.2(\text { at } \Delta X \leqslant 1.5), \\
I=\frac{E_{\mathrm{gi}}^{2}}{E_{\mathrm{gV}}^{2}+E_{\mathrm{gi}}^{2}} \\
E_{\mathrm{g} \Sigma} \cong E_{\mathrm{gV}}\left(1+I^{1 / 2}\right) \cong E_{\mathrm{gv}}(1+0.5 X) .
\end{gathered}
$$

Hence, for $\Delta X \approx 0.7$ the, ionic component of forbidden gap consists of about $35 \%$, for $\Delta X \approx 1.5$ - about $100 \%$.

In the scheme of extended bonds, which was considered by Harrison et al., for different matrix elements $s s \sigma, s p \sigma, p p \sigma, p p \pi$ a rather general relation was obtained:

$$
V_{l l^{\prime} m}=\eta_{l l^{\prime} \eta} \frac{h^{2}}{m^{*} r_{A B}^{2}} \sim \frac{1}{r_{A B}^{2}}
$$

and, moreover, for covalent tetrahedral crystals coefficient $\eta_{l l^{\prime} \eta}$ has definite values, the same for different materials: $\eta_{l l^{\prime} \eta}=1.39,1.88,3.24,0.93$. Hence, we have the universal dependence of the $E_{\mathrm{g}}$ on the lattice constant $L_{A B}$ :

$$
E_{\mathrm{gV}}=\frac{A}{r_{A B}^{2}}=\frac{A}{L_{A B}^{2}}
$$

where the lattice constant $L_{A B}=2 / \sqrt{3} r_{A B}$ can be calculated based on the wellknown values of the valence radius of the atoms of crystals under the analysis:

$$
L=\frac{2}{\sqrt{3}} r_{A B}, \quad r_{A B}=a_{A}^{\mathrm{V}}+a_{B}^{\mathrm{V}} .
$$

This means that $E_{\mathrm{g}}(L)$ in some approximations (first of all, for interatomic distances when $\mathrm{sp}^{3}$ hybridization dominates) the simple quadratic relation takes place:

$$
E_{\mathrm{g}} \sim \frac{1}{L^{2}} \equiv \frac{1}{r_{A B}^{2}}
$$




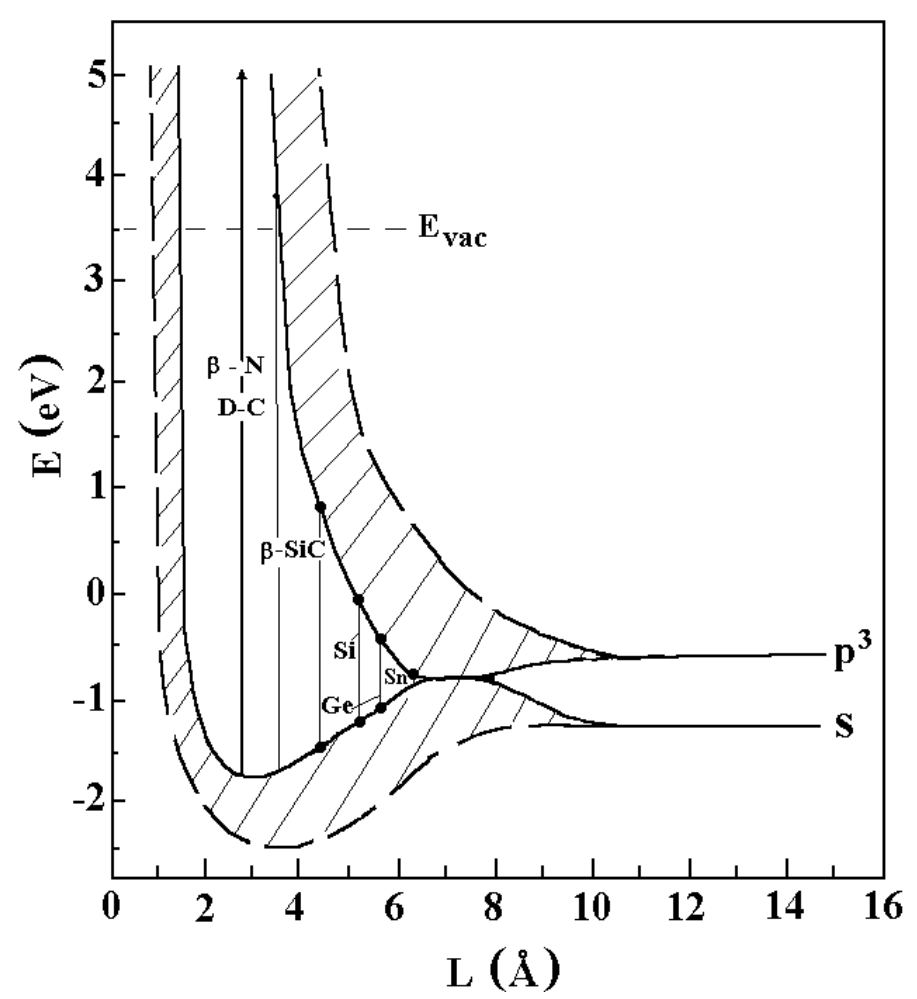

Figure 1. Energy bands for FC-cubic crystal modification of the fourth group element of the periodic system as a result of the sp-3 hybridization of valence electron orbitals, in the dependence of the lattice constant L [1-3].

More exact relation $E_{\mathrm{g}}(L)$ can be obtained from figure 1, which is demonstrated in figure 2 and which up to $L \approx 5.5 \AA$ is in good qualitative agreement with simple formula $E_{\mathrm{g}} \sim 1 / L^{2}$, figure 2 (curve 1 ).

To obtain the quantitative agreement we obtain the dependence $E_{\mathrm{g}}(L)$ from the general view of band structure curves, obtained theoretically, as demonstrated in figure 1 , which in the middle part follows the relation $E_{\mathrm{g}} \sim 1 / L^{2}$.

The mechanical parameters are determined by elastic energy

$$
E_{\mathrm{el}}=\frac{3}{4}\left(C_{11}-C_{12}\right) \Delta x^{2} \sim \frac{A}{L^{5}}
$$

for covalent bonds and for mixture (ionic-covalent) bonds accordingly $\sim A / L^{3.5}$. So, the melting temperature, which is proportional to the energy of chemical bonds:

$$
T_{\text {melt }} \sim E_{\text {el }}\left(\Delta x_{\text {max }}\right) \sim \frac{B}{L^{1.5 \div 3}}
$$

and hardness

$$
\begin{gathered}
H \sim\left(C_{11}-C_{12}\right) \sim \frac{C}{L^{2}} \\
\omega_{\mathrm{opt}}^{2}=\frac{C_{\Sigma} k}{M L^{2}} \sim \frac{D}{L^{4} M} .
\end{gathered}
$$


An important conclusion is that there is another important relation - between $E_{\mathrm{g}}$ and electron affinity (optical work function) X:

$$
E_{\mathrm{gV}}(L)+X(L)=5.35-\Delta E_{V} \approx 5.5 \mathrm{eV}
$$

where correction term $\Delta E_{\mathrm{V}} \sim\left(L-L_{\mathrm{DM}}\right) / 2 L$ (here $L_{\mathrm{DM}}$ is the minimum value of $L$ in dependence $E(L))$ being as a rule a small correction $(<0.5 \mathrm{eV})$ determined as the dependence of valence band edge on the lattice length (i.e. it is near zero for diamond, about $0.25 \mathrm{eV}$ for $\mathrm{Si}$ and $\mathrm{Ge}$ and about $0.5 \mathrm{eV}$ for $\mathrm{Sn}$ ).

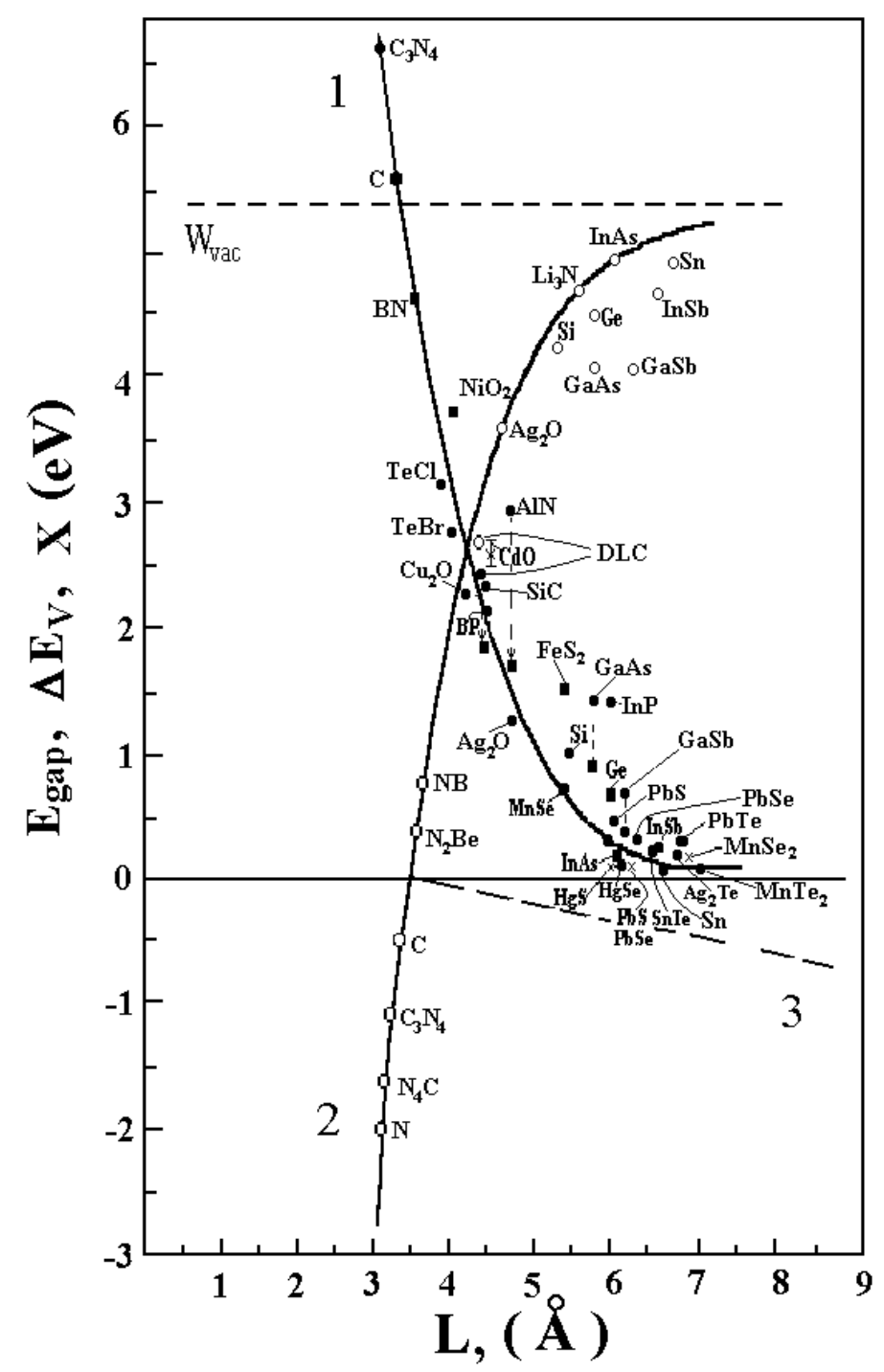

Figure 2. Theoretical dependences of the energy gap $\mathrm{E}_{\text {gap }}(1)$, electron affinity $\mathrm{X}(2)$, correction value $\Delta \mathrm{E}_{\mathrm{V}}$ (3, dotted lines) and experimental data for different cubic crystal materials (points) as the function of the lattice constant L. On the left part of figures 1, 2 the parameters for a set of hypothetical materials are shown. 
Thus, knowing the value of $E_{\text {gap }}$, we can calculate from the value of the optical work function $X$. In particular, it is possible to predict low values of $X$ for a set of crystals - for $\mathrm{Cu}_{2} \mathrm{O}(X \approx 3 \mathrm{eV}), \mathrm{Ag}_{2} \mathrm{O}(X \approx 3.5 \mathrm{eV}), \mathrm{NB}(X \approx 1 \mathrm{eV}), \mathrm{CdO}$ $(X \approx 2.5 \mathrm{eV}), \mathrm{C}_{3} \mathrm{~N}_{4}(X \approx-1 \mathrm{eV})$ etc. as well as to propose the corrections of the $E_{\mathrm{g}}$ for a set of important, but not sufficiently studied, materials with FC lattices, such as $\operatorname{Ag}_{2} \operatorname{Se}\left(E_{\mathrm{g}} \approx 1.2-1.7 \mathrm{eV}\right) \operatorname{HgSe}\left(E_{\mathrm{g}} \approx 0.4-0.6 \mathrm{eV}\right), \mathrm{TiO}\left(E_{\mathrm{g}} \approx 2.8-3 \mathrm{eV}\right)$ (instead of $0.15 \mathrm{eV}$ ).

In the case of bi- or more component crystals non-symmetry of bound electrons density takes place, and the "ionic" component of the energy band can be taken into account using an approximation for electronegativity of elements $X_{A}, X_{B}$ and $L$, Pauling relation for the degree of ionicity (6). Hence, the important characteristic values (like energy gap $E_{\mathrm{g}}$, electron affinity, elastic energy $E_{\mathrm{el}}$ and hardness, melting temperature $T_{\mathrm{m}}$ as well as $L O$-phonon energy) can be represented as functions of the parameter $L$. In particular, $E_{\mathrm{g}}=A\left(m^{*}\right) / L^{2}$ (where universal constant $A$ is only slightly dependent on the effective mass), $E_{\text {el }}=A / L^{5}$ or $\sim\left(20-2 a_{i}\right) / L^{3 / 5}$ respectively for one- and two-element cubic crystals, $T_{\mathrm{m}} \sim C / L^{1.5-3}, \omega_{L O} \sim C^{*} / L^{2}$, figures 2,3 .

The extreme case is connected when the smallest lattice constant $L$ (near minimum dependence $E(L)$ ) predicts the largest (for tetrahedral structure) values of $E_{\mathrm{gv}}$, unusually large negative electron affinity $X_{\max }$ and other extreme parameters (like melting temperature $T_{\mathrm{m}}, \omega_{L O}$, hardness $H$ etc.). In particular, $E_{\mathrm{gV}}^{\max }=8-10 \mathrm{eV}$, $L_{\min }=2.6 \AA, X_{\max }=-(1.5-2) \mathrm{eV}, T_{\mathrm{m}}^{\max }=4500-5000 \mathrm{~K}, \omega_{L O} \approx 80 \mathrm{meV}$, $H \approx(150-160) \mathrm{GPa}$ have been predicted. These parameters substantially exceed the values for natural diamond, the hardest material known at present. The chemical formulas for such materials are $\mathrm{C}_{3} \mathrm{~N}_{4}, \mathrm{C}_{3} \mathrm{~N}_{4-x} \mathrm{H}_{x}$ etc.

One should mention that the values of the effective lattice constant for the quantum-size structures have to be different from those for the bulk structures. The described approach can be used for the estimation of the variation of the characteristic constants for all quantum-size structures (2D, 1D, 0D).

The developed approach can be used for the estimation of some important parameters of the new extremely hard materials. This is the carbonized boronitride cubic crystal (BCN), the synthesis of which has been performed under high pressure and high temperature using the catalysis. The $X$-ray measurements have proven that the obtained crystals have FC cubic diamond configuration with lattice constant $L \approx 3.6 \AA$ which is somewhat lower than for the diamond and a little bit higher than for the second (after diamond) materials with cubic crystalline structure $-\mathrm{BN}_{2}$ in the row of hardnesses. Hardness has been experimentally investigated to be approximately $80 \mathrm{GPa}$ which is only slightly lower than for the diamond.

Our prediction coincides with the mentioned parameters. Moreover, the optical refractive index measured by us is also in good agreement with the predicted curve [3]. Besides, we could be able to estimate such fundamental parameters as optical work function X, energy gap, phonon energy $\omega_{L O}$, melting temperature $T_{\mathrm{m}}$. Being very hard this material has near zero value of electron affinity, which is prospective for photo- and field emission, for ultrahigh temperature electron devices etc. 


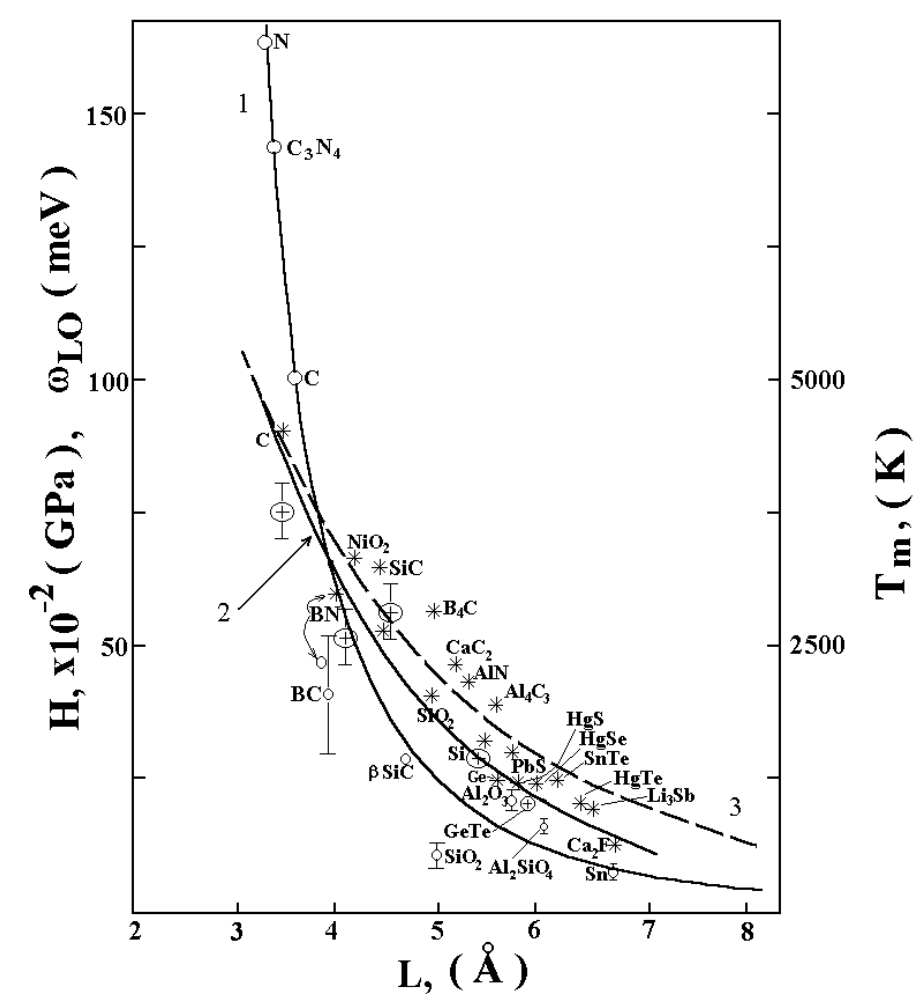

Figure 3. The dependences of mechanical hardness (in GPa, scale Wicklers open circles, points - experimental, solid line - theoretical curve $\sim L^{-n}$ ), melting temperatures $\mathrm{T}_{\mathrm{m}}$ and optical phonon energy $\omega_{\mathrm{ph}}$ (stars and crossed circles) as a function of the lattice constant L.

Even more extreme materials which have the hypothetical crystalline structure are cubic nitrocarbon $\mathrm{C}_{3} \mathrm{~N}_{4}$ (similar to well-known cubic $\mathrm{Si}_{3} \mathrm{~N}_{4}$ ). The predicted parameters of this substance are presented in the end of the table 1 . It is seen that such parameters as $X, H, T_{\mathrm{m}}$ are even more outstanding than those of the hardest material like diamond (negative electron affinity, the highest melting temperature etc.).

Besides the predicted parameters of the mentioned materials, a number of other cubic-structure semiconductor materials can be predicted. Let us consider carbon and nitride-based substances (based on the substances with minimum valence radius: 0.77 and $0.71 \AA$, respectively). These are fourth group elements that form the alloys with the mentioned substances: $\mathrm{SiCGe}, \mathrm{Si}_{x} \mathrm{Ge}_{y} \mathrm{~N}_{z}(x+y=3, z=4), \mathrm{BC}_{x} \mathrm{~N}$ $(\mathrm{N}=1,2, \ldots), \mathrm{C}-\mathrm{H}_{x}$ etc. These new materials demonstrate a large number of useful parameters, see table. In particular, the value of $\omega_{L O}$ can give the estimation of carrier mobility $\mu \approx 2 \pi e /\left(m^{*} \omega_{\text {opt }}\right)$. It is also possible to create "intermediary" materials, say, between diamond and $\mathrm{Si}, \mathrm{Ge}$, to more easily obtain $\mathrm{SiC}_{x} \mathrm{Ge}$ with the properties similar to those of SiGe layers. The C Si, Ge, SiGe or III-V compounds can be used for a catalytic action (in order to create a cubic configuration).

Some corrections to this approach should be made taking into consideration the 
Table 1. Basic parameters of the qubic crystals(corrections for the ionicity are given in brackets)

\begin{tabular}{|l|l|l|l|l|l|l|l|}
\hline Material & $\mathrm{R}_{\mathrm{v}}, \AA$ & $\mathrm{L}_{\mathrm{ef}}, \AA$ & $\mathrm{E}_{\mathrm{g} \Sigma}, \mathrm{eV}$ & $\mathrm{X}, \mathrm{eV}$ & $\mathrm{H}, \mathrm{GPa}$ & $\omega, \mathrm{meV}$ & $\mathrm{T}, \mathrm{K}$ \\
\hline$\beta-\mathrm{C}$ & $0.77 \times 2$ & 3.4 & 5.5 & \pm 0.5 & 100 & 145 & 4300 \\
\hline $\mathrm{Si}$ & $1.18 \times 2$ & 5.4 & 1.1 & 4.3 & 18 & 30 & 1700 \\
\hline $\mathrm{Ge}$ & $1.39 \times 2$ & 6.0 & 0.7 & 4.6 & 12 & 25 & 1200 \\
\hline$\beta-\mathrm{SiC}$ & 1.95 & 4.3 & 3.1 & 2.0 & 40 & 55 & 3000 \\
\hline $\mathrm{GeC}$ & 2.6 & 4.8 & 1.5 & 4.0 & 25 & 40 & 2550 \\
\hline $\mathrm{SiGe}$ & 2.57 & 5.7 & 0.9 & 4.4 & 14 & 28 & 1400 \\
\hline
\end{tabular}

\begin{tabular}{|l|l|l|l|l|l|l|l|}
\hline $\mathrm{SiCGe}$ & 2.22 & 5.1 & 1.5 & 4.2 & 20 & 35 & 2100 \\
\hline $\mathrm{SiC}_{2} \mathrm{Ge}$ & 2.00 & 4.9 & 1.7 & 4.0 & 22 & 42 & 2500 \\
\hline $\mathrm{Si}_{3} \mathrm{~N}_{4}$ & 1.8 & $\begin{array}{l}\approx 4.1 \\
\pm 0.2\end{array}$ & $3.5 \div 4$ & 2 & 55 & 55 & 3800 \\
\hline
\end{tabular}

\begin{tabular}{|l|l|l|l|l|l|l|l|}
\hline $\mathrm{Si}_{2} \mathrm{~N}_{4} \mathrm{Ge}$ & 1.8 & 4.3 & 3.4 & 4.1 & 40 & 55 & 3000 \\
\hline $\mathrm{SiN}_{4} \mathrm{Ge}_{2}$ & 2.16 & 5 & 1.2 & & 21 & 36 & 2150 \\
\hline $\mathrm{BN}$ & 1.68 & 3.75 & $4.2(3.8)$ & $+0.5-1$ & $70-80$ & 70 & 3600 \\
\hline$\beta-\mathrm{BC}_{2} \mathrm{~N}$ & 1.61 & 3.6 & $6(5)$ & $0-0.5$ & $85-90$ & $75-80$ & $\begin{array}{l}4000- \\
4200\end{array}$ \\
\hline$\beta-\mathrm{C}_{3} \mathrm{~N}_{4}$ & $\approx 1.46$ & 3.2 & $7 \div(6)$ & $1-1.5$ & $\begin{array}{l}140- \\
170\end{array}$ & 95 & 5000 \\
\hline
\end{tabular}

\begin{tabular}{|l|l|l|l|l|l|l|l|}
\hline $\mathrm{GaAs}$ & 2.6 & 5.75 & $1.0(1.4)$ & 4.5 & 12 & 30 & 1500 \\
\hline $\mathrm{GaCAs}$ & 2.2 & 5.1 & $1.5(1.8)$ & 4.2 & 22 & 35 & 2000 \\
\hline $\mathrm{GaC}_{2} \mathrm{As}$ & 2.0 & 4.9 & $1.7(2)$ & 4.0 & 28 & 40 & 2300 \\
\hline $\mathrm{InAs}$ & 2.8 & 6.1 & $0.8(1)$ & 4.6 & 8 & $15-20$ & 1200 \\
\hline $\mathrm{InCAs}$ & 2.5 & 5.6 & $1(1.2)$ & 4.4 & 12 & 28 & 1700 \\
\hline $\mathrm{InC} \mathrm{As}_{2} \mathrm{As}$ & 2.2 & 5.1 & $1.5(1.8)$ & 4 & 22 & 35 & 2000 \\
\hline $\mathrm{AlAs}$ & 2.7 & 5.8 & $0.8(1)$ & 4.6 & 11 & 45 & 2000 \\
\hline $\mathrm{AlCAs}$ & 2.3 & 5.2 & $1.4(1.6)$ & 4.2 & 16 & 30 & 1900 \\
\hline $\mathrm{AlC}{ }_{2} \mathrm{As}$ & 2.1 & 5 & $1.3(1.7)$ & 3.9 & 20 & 35 & 2100 \\
\hline $\mathrm{Si}_{1,2,3} \mathrm{~N}_{4} \mathrm{Ge}_{3,2,1}$ & $\approx 1.9-2$ & $\approx 4.8$ & $\approx 1.8$ & $\approx 3.8$ & $\approx 25$ & $\approx 45$ & $\approx 2700$ \\
\hline $\mathrm{In}_{1,2,3} \mathrm{~N}_{4} \mathrm{As}_{3,2,1}$ & $\approx 2.1$ & $\approx 5$ & $\approx 1.4$ & $\approx 3.7$ & $\approx 27$ & $\approx 40$ & $\approx 2200$ \\
\hline $\mathrm{Ga}_{1,2,3} \mathrm{~N}_{4} \mathrm{As}_{3,2,1}$ & $\approx 1.9$ & $\approx 4.8$ & $\approx 1.6$ & $\approx 3.8$ & $\approx 30$ & $\approx 45$ & $\approx 2600$ \\
\hline $\mathrm{Al}_{1,2,3} \mathrm{~N}_{4} \mathrm{As}_{3,2,1}$ & $\approx 2$ & $\approx 4.9$ & $\approx 1.7$ & $\approx 4.0$ & $\approx 28$ & $\approx 40$ & $\approx 2300$ \\
\hline
\end{tabular}


elastic stressing due to the mismatch of the atomic valence radii. So, for $\mathrm{SiC}_{x} \mathrm{Ge}$ it is possible to reduce the internal stress, which is rather high for pure SiGe crystals. The estimation of the stress value can be made from the difference of the radii and pieso-constants of the basic materials.

The addition stressing forces take place in case of ultrasmall clusters (i.e., nanocluster case). Here the surface energy (and surface tension) becomes important in order to change the effective valence radius and hence the effective lattice constant $L$. The value of the pressure can be estimated from the formula of Laplace pressure:

$$
P=\frac{2}{R} \sigma_{12}
$$

where $\sigma_{12}$ is an energy of the surface tension at the interface of the nanoparticle with the surroundings.

In comparison with the bulk case, the pressure for $R \approx 1-5 \mathrm{~nm}$ increases from 2 to 3 orders of magnitude and reaches the flexibility limit. If this value is of the order of $\Delta L / L \approx 10 \%$ it is possible to estimate the change of parameters of some materials. In some cases $\Delta E_{\mathrm{g}} \approx 20 \%$.

Another important factor here is the dielectric (or metal-like) surroundings in which the nanoparticles are embedded. Here a good approximation is the method of the effective medium. This method permits to find an effective dielectric constant from the known values of dielectric constants of the constituents (Gaertner et al. approximation):

$$
\varepsilon_{\mathrm{eff}}=\varepsilon_{1} \frac{\varepsilon_{2}(2-c)+\varepsilon_{1} c}{\varepsilon_{1}(2-c)+\varepsilon_{2} c}
$$

where $c$ is the relative part of the phase 1 .

So, the effective medium will radically change the fundamental parameters in the case of quantum dots. The experimental example of this effect is checked for the nanocrystals of porous silicon. Here we have used the proposed approximation for the calculation of the exciton energy and linear size parameters from the data of the exciton luminescence spectra measured at low temperature. The estimated exciton binding energy $E_{\mathrm{ex}} \approx 90 \mathrm{meV}$ which is unusually high in comparison with the value for the bulk silicon:

$$
E_{\mathrm{ex}}=\gamma \sqrt{\frac{\pi}{2}} \bar{N} E_{\mathrm{ph}} \frac{\varepsilon_{\infty}}{\varepsilon_{0}-\varepsilon_{\infty}} .
$$

From the estimation of $E_{\mathrm{g}}=E_{\mathrm{ex}}+E_{P L}$ and the dependence of the band-gap energy on the diameter of Si quantum dots it is possible to determine the quantum dot size. It is approximately equal to $\approx 3.4 \mathrm{~nm}$ in our case.

Therefore, in the case of quantum-size structures (thin layers, rods, zero-dimensional nanoparticles etc.) the additional factors are to be taken into account. They are the effect of the polarising ambient surface pressure, limitation in dimensions. Hence, the estimation of the basic parameters needs the above-mentioned factors to be taken into account. 


\section{Conclusions}

In conclusion, in this communication we analyse the energy parameters important in vacuum micro- and nanoelectronics such as the work function (electron affinity), energy gap $\mathrm{E}_{\mathrm{g}}$ and lattice constant $\mathrm{L}$ within the framework of the known band structure theory. The comparison between our experimental data and the reference ones, in particular, for the diamond-like carbon films, illustrate a rather good agreement with the obtained theoretical dependences: $\mathrm{E}_{\text {gap }}(\mathrm{L}), \mathrm{X}(\mathrm{L})$. This makes it possible to predict the structure of the composites of the hydrogen-enriched diamond-like carbon films, to obtain the work function $\mathrm{X}$ from the values of $\mathrm{E}_{\text {gap }}$ and vice versa: $\mathrm{E}_{\text {gap }}+X=5.3 \mathrm{eV}-\Delta E_{\mathrm{V}}$, as well as to predict new materials of cubic crystal configuration with unique properties (i.e., the highest melting temperature, the largest optical phonon energy and the largest negative electron affinity).

\section{References}

1. Litovchenko V. // Phys. Rev. B, 2002, No. 65, p. 153108-1.

2. Solozhenko V.L., Dub S.N., Novikov N.V. // Diamond Related Mater., 2001, No. 10, p. 2228.

3. Solozhenko V.L., Kondratenko O.S., Litovchenko V.G., Dmitruk N.L. // Superhard Materials, 2002, No. 2, p. 78. 


\section{Аналіз фундаментальних характеристик алмазоподібних кристалів і низьковимірних структур}

\section{В.Г.Литовченко}

Інститут фізики напівпровідників НАН України, 03028 Київ, проспект Науки, 45

Отримано 8 квітня 2003 р., в остаточному вигляді - 12 лютого $2004 \mathrm{p}$.

Запропонований принцип системного опису параметрів алмазоподібних кристалів з тетраедричною структурою елементарної комірки та з валентним типом хімічного зв'язку, що базується на розрахунку постійної гратки. Запропонований підхід дозволяє передбачити такі фундаментальні параметри речовин, як ширину забороненої зони $E_{\mathrm{g}}$, електронну спорідненість (оптичну роботу виходу) $X$, механічну твердість $H$, температуру плавлення $T_{\mathrm{m}}$, граничну частоту оптичних фононів та ін. Пропонується таблиця названих параметрів для численних речовин, в тому числі нових. Для матеріалів зі змішаним іонно-ковалентним типом хімічного зв'язку розраховані поправки, використовуючи принцип електронегативності Полінга. Порівняння з експериментом демонструє добре узгодження.

Ключові слова: систематизація алмазоподібних кристалів, електронна спорідненість, температура плавлення

PACS: 81.05.Bx, 81.05.Cy, 74.78.-w 
